\title{
Moral ape philosophy
}

\author{
Jelle de Boer
}

Received: 20 December 2010/Accepted: 5 June 2011/Published online: 17 June 2011

(C) The Author(s) 2011. This article is published with open access at Springerlink.com

\begin{abstract}
Our closest relative the chimpanzee seems to display proto-moral behavior. Some scholars emphasize the similarities between humans and chimpanzees, others some key differences. This paper aims is to formulate a set of intermediate conditions between a sometimes helpful chimpanzee and moral man. I specify these intermediate conditions as requirements for the chimpanzees, and for each requirement I take on a verificationist stance and ask what the empirical conditions that satisfy it would be. I ask what would plausibly count as the behavioral correlate of each requirement, when implemented. I take a philosophical look at morality using the chimpanzees as a prism. We will talk of propositional attitudes, rationality and reason in relation to the chimps. By means of the chimps I intend to arrive at a notion of objective morality as conceived from a first person point of view in terms of propositional attitudes and reasons.
\end{abstract}

Keywords Chimpanzees · Morality - Frans de Waal - Creature construction

\section{Introduction}

Old chimpanzee Peony shuffles towards a climbing frame in the outdoor enclosure to join several conspecifics on top, but the climbing is too difficult on this cold day. Her arthritis is acting up. Then an unrelated female moves behind her, puts both hands on Peony's behind, and pushes her with some effort. So Peony gets where she wants to be.

\section{J. de Boer $(\bowtie)$}

Philosophy Department, University of Amsterdam, Oude Turfmarkt 141-147, 1012 GC Amsterdam, The Netherlands

e-mail: j.s.deboer2@uva.nl

J. de Boer

Delft University of Technology, Delft, The Netherlands 
In another enclosure we see Krom pulling a rubber tire with water in it, but he doesn't seem to understand that he should first release the tire from the other six tires that hang in front of it. Then, after 10 min when Krom gives up, and walks away, Jakie approaches the tires. He removes the six tires one by one, grabs the tire Krom liked, and brings it to him, carefully, without losing water.

It can also be observed among chimpanzees that a dominant individual shares food with a lower ranking individual, one he could easily rebuff.

Primatologist Frans de Waal collects such altruistic ape casuistry (1996, 1997, 2007). He argues that chimpanzees are capable of empathy. They regularly help and console each other. Empathy, help, and consolation are the 'building blocks' of morality, as he called it in his 1996 book Good Natured, and on which he elaborated in his Tanner Lectures on Human Values at Princeton in 2003 (2006). De Waal firmly puts himself in the Humean tradition, with its emphasis on empathy concerning morality and its naturalist method.

Nevertheless, the chimpanzee is still quite removed from moral man. De Waal highlights interesting similarities but there are also important differences. One can have various doubts about the moral quality of chimpanzee cooperative behavior. Do the chimps know, for example, what they are doing when they help a conspecific? Are they in the relevant way aware of their good deeds? Doesn't their friendliness come too easily, at too little cost? Are their motives in order, don't they really cooperate or help to collect some future gain later on ${ }^{1}$

The topic of this paper is to formulate a set of rationality requirements going from the sometimes-helpful chimpanzee towards moral man. I sympathize with De Waal's project, I'll do this in naturalistic fashion. I'm taking my cue from Bennett's (1964) essay Rationality, which worked from dancing bees to what Bennett found to be the important characteristics of language. We know that bees can tell each other where to find food, through certain bodily movements that indicate distance and angle to the sun. It nonetheless seems exaggerated to say they have a language. Bennett's question was what more is needed, in terms of extra rationality specifications, to make a fictional linguistic bee from an actual honey-bee. Likewise, my challenge is to think up a rational development from Pan troglodytes to Homo sapiens, while looking at moral behavior.

Surely, there is no unique best way to do this, since many requirements could be conceived. Nor is there a pre-established method for comparing different sets. But plausibility should at least derive from the requirements themselves, in as much as they should be self-evident or else argued for, and of course the requirements should be well connected.

In other words, this paper is engaged in what Paul Grice has called "creature construction'. "The method which I should like to apply," Grice said, "is to construct (in imagination, of course) according to certain principles of construction, a type of creature, or rather a sequence of types of creature, to serve as a model (or models) for actual creatures."2 By means of this sequence Grice wanted to rethink

\footnotetext{
1 Such points are voiced by De Waal's critics at his Tanner Lectures, most notably by Korsgaard (2006) and Kitcher (2006).

2 Grice (1975) p. 37.
} 
the basics of psychology (judging and willing). We will be concerned with some basics of morality.

So the aim of the paper is specifying a set of intermediate conditions between helpful chimp and moral man. I specify these conditions as requirements for the chimpanzees, and for each requirement I take on a verificationist stance and ask what the empirical conditions that satisfy it would be. I ask what would plausibly count as the behavioral correlate of each requirement, when implemented. Not anything goes, of course; as Grice said, we had "better keep a close eye on the actual world in order to stay within the bounds of the possible." ${ }^{3}$ We should stay as closely as possible to what actual chimpanzees have to offer, so we will regularly check with the empirical literature.

I do not focus on selection pressures as a biologist would do, or on cognitive powers as a comparative psychologist would. Instead we will talk of propositional attitudes, rationality, reasons. I propose to take a philosophical look at morality using the chimps as a prism. I will stop when we have reached a seemingly good measure of objectivity from the first person point of view. ${ }^{4}$

\section{Method and context}

We will discuss three rationality requirements. I devote a section to each of them. Section "Belief" is about the propositional attitude belief. A moral chimpanzee should not just manifest helping behavior. It should do this in a certain state of mind. It should have a belief about what it is doing. How could we ascribe this to a chimpanzee? Section "Reason" discusses the 'why?' of helping behavior. We want our chimpanzees to help others for the right kind of reasons. How could this be decided? Section "Mutual beliefs" shifts the focus to those who are being helped, and asks whether their expectations should make a difference to the moral attitude of the helper.

The method is as follows. I argue for the first requirement, and then ask what would be needed to satisfy this requirement, and what would be the corresponding behavior so that an observer studying the apes would say, "yes, this is quite plausible, these are apes that seem to live up to this requirement." This then presents us with a problem, of this kind: "but this situation you just indicated also leaves room for ... (to be filled in) behavior, and that is clearly not moral behavior." Subsequently I will try to answer this by adding a new requirement. The problems that come up are simply those that I think are the most obvious, given and constrained by the stage the engineered apes are in.

It is not my aim to explore how the empirical conditions that I think would match the rationality requirements could possibly emerge. That might be interesting, perhaps, but it is a different matter.

\footnotetext{
3 Ibid p. 38.

${ }^{4}$ Philip Kitcher $(1998,2006)$ also explores the space between chimpanzee proto-morality and more fully fledged morality. Kitcher does not develop a sequence of creatures but proposes a grid, a set of dimensions, (intensity, range, extent, and skill of altruism), to make comparisons in this space. His approach is different but his dimensions have been helpful. See also Harnden-Warwick (1997).
} 
Before starting, however, I propose to shift the scene and move away from the grounds where De Waal typically makes his observations. I am interested in a wildlife collective action problem as the context for my questions. Nothing essentially hinges on this. Doing so will just more clearly bring out the points that I want to discuss.

We move to the Taï National Park, Ivory Coast, Africa. In this park Christophe Boesch and Hedwige Boesch have been studying wild chimpanzees for more than two decades. ${ }^{5}$ The Taï chimpanzees go out on a collective hunt occasionally, in bands of three to four, mostly after the Red Colobus monkey. The collective performance is not just a happy coincidence emerging out of separate individuals chasing a prey at the same time. The fieldworkers argue that the Taï chimpanzees display organization and that there is division of labour among them. The Boesches have documented various roles: driver, blocker, chaser, ambusher; with the chimps taking turns as the situation demands. It isn't an easy job for these apes, as they are not simply hard-wired to perform these roles. They have to learn this. It is especially the anticipatory ambushing and blocking that strongly correlate with age. For most chimpanzees it takes 20 years to become a good hunter.

Taï hunting seems to depend on the habitat. At Gombe, some 5,000 miles to the East, chimpanzees successfully hunt Red Colobus on their own because their trees are relatively short and further apart. The Taï forest, by contrast, has tall trees, is densely spaced, and has more continuous canopy, offering plenty of room to escape for the swift monkey. Therefore, the Taï chimps cannot catch this prey by themselves. It requires teamwork. ${ }^{6}$

Now, when a Taï hunt is going on, invariably there are also passive onlookers, bystanders who do not participate but just watch. Since most hunts are successful, the collective work typically terminates with one lucky individual catching the prey. And just as typically, this ape will subsequently be quickly cornered by others begging for a share. So who to give something to? At random, trade-based, threatbased, sex-based, need-based-how? The field results suggest a striking pattern: the chimpanzees prefer to share with other hunters, i.e. with those who participated in the hunt. Fellow hunters, the chasers and the blockers, gain significantly more meat than the bystanders.

I will use the Taï group hunt and the sharing as a central example. We will not discuss other possible aspects of chimp proto-moral behavior. Much of the force of De Waal's argument of course derives from the broadness of his casuistry: the chimp cases of helping, empathy, consolation, and reciprocity. My strategy in this paper is different. We will focus on just one example of such proto-morality-the sharing behavior after the Taï group hunt-and see how we can develop this into a

\footnotetext{
5 Boesch and Boesch (1989) and Boesch (1994, 2003).

${ }^{6}$ Of course there is controversy among primatologists as to whether the Boesches are entirely correct in their descriptions and interpretations of the group hunt. Isn't it an intriguing example of individual chasing actions, somehow interlocking, after all; and no collective plan? This worry need not concern us here. The Boesch story is well established and convincing enough for our thought experiment, so I simply assume that it is correct. E.g. Tomasello and Call (1997). Cf. the discussion between Tomasello et al. (2005) and Boesch (2005).
} 
piece of more fully-fledged morality. In the conclusion I will briefly generalize beyond the Taï sharing case.

\section{Belief}

As De Waals anecdotes have already told us, chimpanzees are social creatures. But what follows from this? After all ants and termites are social creatures too. A first requirement is that our ape must not just respond to its environment, its behavior must not just be a matter of biochemistry or even of stimulus response. The ape should have an inkling of what it does. It should make sense to ascribe a propositional attitude to the helping chimpanzee, namely belief. Chimpanzee $\mathrm{P}$ doesn't just share food with Q, P also believes that it shares food with Q. Now how can we tell the difference between these two situations?

Consider a more simple case first. A sunflower is a flower that constantly repositions itself so that it is always facing the sun. So we might say that a sunflower, through the bend in its stem and the posture of the corolla, corresponds to the position of the sun. OK, but does a sunflower in a certain position at 3 p.m., also believe that the sun is at the corresponding spot? That seems an odd thing to say, but why? The reason is that an intrinsic part of believing involves being mistaken. To believe something is to be fallible. Donald Davidson argued in Rational Animals (1982) that to believe something implies that the believer grasps this fallibility. He can make the distinction between 'this is the case' and 'I believe this is the case'. A creature manifests a grasp of this distinction possibly through the emotion of surprise. Because when I am surprised it is because I believed that something is the case ... which isn't the case.

Thus one should be able to grasp the distinction between 'this is the case' and 'I believe this is the case'. And this, Davidson claims, presupposes the notion 'this is the case', a sense of objectivity thus. Now where does that come from? Through triangulation with other people, says Davidson. Others provide you with their impressions of an object or event from their point of view, and thereby you can fine tune your own impression.

Let's get back to our Taï chimpanzees. As said, chimps in the captor role share the loot with others, contingent on participation in the group hunt, and not for example on dominance. Thus a noteworthy case would be a dominant captor sharing with a fellow hunter of subordinate rank.

Let's call the dominant ape Alfa, and the subordinate Beta. Alfa shares food, while he could easily have dismissed Beta, securing a better lunch for himself. We see that Alfa shares the food with Beta, and now we want to say that Alfa also believes he should be doing this. This means, if we follow Davidson, that Alfa should be able to grasp the distinction between something being the case and believing something to be the case. The case here is: should-be-sharing-food. Then, I suggest, Alfa could manifest a command of the distinction if he first makes a mistake about the sharing and subsequently corrects it. A conceivable scenario would be this. Beta tries to take some food from out of Alfa's hands, with Alfa at first refusing to let the food go and even turning his back on Beta. But then Alfa 
swings back, moves towards Beta, and splits the food, with a certain expression on his face that indicates his acknowledgement of this sort of mistake. ${ }^{7}$

This expression is not one of surprise, presumably, because surprise does not come close to the function of manifesting a failure to give to others. Alfa would be surprised, for example, if he suddenly found out that it was a piece of wood that he was holding in his hands and was now offering to Beta. The kind of mistake that is interesting for our purposes here, however, is a failure to share in the non-egoistic sense. Let us assume that the corresponding facial expression is a submissive grin (which real chimps employ), because what is at stake is something like an internalized form of surrender to a group of disapproving bystanders. (At the end of this tale this emotion of internalized submissiveness should be transformed into moral guilt.)

Thus Alfa's lunch appetite prevailed only until he recalled that sharing was the correct thing to do. This is possible, in Davidson's view, because others can inform one that one is mistaken. Primitive communication can suffice for triangulation if the matter is not too difficult. The bystanders may for example bark, grin, or give a punch. Or they may give an encouraging look or a friendly pat on the back. Chimps have a repertoire for voicing approval and disapproval. ${ }^{8}$ Thus can 'sharing food is the thing to do' be objectified in Davidsonian style.

I have augmented Davidson's triangulation with social appraisal in order to get not only the propositional attitude 'belief' but also a 'should' in the content of that belief. The bystanders do not just provide a different angle if one happens to see things incorrectly, their disapproval also incorporates an appeal; they exert motivational pull. This modification is appropriate for our purposes, since morality of course makes demands.

Now this raises three issues. First, why do we need the approval-disapproval triangulation machinery for getting a measure of objectivity in the first place? I have assumed that Davidson's social route towards rationality is correct, but of course this can be questioned. Can't we get objective beliefs without communication? Second, why would the bystanders disapprove of something that is not their business, why would they possibly bother about some hunters quarrelling? Third, if this is the way it works, should we then not say that the captors are merely smart egoists, prudent, not making moral progress at all-just busy anticipating some penalties here and rewards there? We will discuss the first and second question in this section, the third in the next section.

\footnotetext{
7 Why concentrate on belief and not on the chimp's desire to share with co-hunters or on his will? I have two answers. The first is that the propositional attitude 'desire' seems to leave much less room for discrimination. At first sight, it is easier to ascribe desires than beliefs to animals. My second answer is that we will address the issue of the right form of the will in section "Belief", when we are going to ask what it would take for us to say that a chimpanzee acts on the basis of a reason. I have chosen to start with 'belief' and not with 'reason' because I think the latter is a stronger notion but I admit that the reverse could be argued too. More importantly, I think that for the analysis it doesn't matter much which comes first. Both are necessary conditions in my view.

${ }^{8}$ Chimpanzees really do have this repertoire, see Van Hooff (1972), Van Hooff and Preuschoft (2003).
} 
The first issue queries whether we cannot get objective beliefs in a more modest way. We know that many animals can learn something through trial and error. ${ }^{9}$ Dogs, dolphins, birds and certainly chimpanzees can. Alfa doesn't share? Next time Beta, when he is the captor, simply turns his back on him. The time after that Gamma does this, and then Delta. No angry barks, no signs of disapproval, just calm silence. When Alfa does share, in subsequent rounds others share with him, too. But no pats on the back, and no joyful shrieks. Over time Alfa can learn in this world that it is better for him to share the loot, that sharing is the thing to do. This is trialand-error learning. At some point he may hesitate a little, i.e. look puzzled, scratch his head, and thereby satisfy the onlooking philosopher. He has a belief, and there has been no communication (in Davidson's sense). Suppose this is so. Thus suppose that our chimps can come to have beliefs through silent reciprocation by the others. It seems that this Tit-for-tat society is conceivably viable. ${ }^{10}$ See, the hunting goes well, the sharing too. Cooperation works fine, and they are all better off. Occasional mistakes are quickly corrected. Everything goes like clockwork.

It can also be argued that this Tit-for-tat society yields no less objective results. Because here too the apes converge on the idea that a captor should share with a fellow cooperator. The difference, of course, is that in the Tit-for-tat world each only relates this obligation to himself. In moral society, in contrast, each finds that a captor should share with any cooperator. Thus, admittedly, both Tit-for-tat society and moral society could be objective but they are objective in different ways. It is only the second kind of objectivity that is moral, where also the not directly involved bystanders sound their disapproval.

Look at what happens if somebody makes a mistake, if somebody doesn't share. In the Tit-for-tat world such an individual gets excluded during the following rounds because he has failed to share on previous occasions. Even if the supposed receiver were to get angry and sound his disapproval, the mistake would not count as a moral mistake. Why? Because it is crucially indistinguishable from any ordinary quarrel, with two creatures trying to get hold of something, and the stronger, or the more persistent, one winning. A moral mistake is a kind of mistake that everybody, involved or not, participating or standing by, disapproves of. Hence, whatever the exact merits of Davidson's social epistemology in general, it is surely right as it concerns the moral sphere. There this kind of convergence is a defining characteristic. $^{11}$

\footnotetext{
${ }^{9}$ For versions of this notion of rationality see for example Searle (1994), Dennett (1995, 370-384), Millikan (2006), Dretske (2006).

${ }^{10}$ For the evolutionary dynamics see for example Skyrms (1996).

11 De Waal alludes to Adam Smiths notion of an impartial spectator (Smith 1759), to account for more objectivity in humans, and so do Philip Kitcher and Peter Singer in their commentaries on his lecture series (Kitcher 2006; Singer 2006). I have chosen to sidestep a discussion of this construct, largely because it looks too much like a deus ex machina in view of my purposes. But now I can briefly indicate, in two points, how the impartial spectator would fit in here. Firstly, in Adam Smith's view the underlying dynamics of the impartial spectator consist in people anticipating each other's emotions and bringing them into harmony. In my attempt the impartial spectator results from rounds of approval and disapproval triangulation which lead to intersubjectivity. Secondly, the Smithian impartial spectator is unbound, away from the particularities of context, and that is of course very noble, but we can ask how he managed to get there. Smith's natural social psychology is perhaps fine, but it seems to lack a rationale. Why all this
} 
This brings us to the second issue: why would the bystanders care about how others share some food between themselves, an event they do not have a stake in? One way to explore this is to turn the issue around and try to think of ways in which the bystanders could be involved, and be parties to what happens. How might they possibly benefit from sounding approval and disapproval from the sideline? Let us add some more possible ways to exchange goods, more tit-for-tat modalities. Here we can also latch onto some real chimpanzee behavior. Pan troglodytus does regularly engage in transactions involving various types of goods. Real chimps sometimes appear to trade grooming for food, help during a fight for sex, food for sex, and so on. ${ }^{12}$

Thus suppose Alfa doesn't share with Beta, and that subsequently bystanders Gamma and Delta send Alfa an angry look or give him a push. Gamma and Delta do this for entirely selfish reasons. Their disapproval is part of a transaction. Gamma owes Beta a grooming session, and now manifesting allied force might write off half of the debt. Delta also shows his teeth, and thereby redeems two bananas from yesterday. Thus Gamma and Delta truck and barter, each having his own selfish reasons to manifest disapproval about Alfa's behavior.

Coalitional society, so to speak, does not make up a moral community yet, of course, but it arguably is a stepping stone towards it. Alliances force the sharing relation beyond the dyadic captor-participant pair. A blocker or ambusher finds that he himself should get a bite when having played his part, and now others voice the same opinion. That is sufficient at this stage of development. ${ }^{13}$

\section{Reason}

At this point it could be objected that our food-sharing chimps are only responding to social approval and material benefits. Aren't they acting on what could be called the wrong kind of reasons? The right kind of reason, in this regard, for sharing is of course that the other one has cooperated. Alfa should share with Beta because Beta has participated in the hunt. Triangulation through approval and disapproval only operates as a correction and instruction device. It does not constitute the reason. In the imaginary apes, at this point of development, cooperation as a reason for sharing should carry its own weight. It should have become relatively ingrained, cut loose from anticipating approval and disapproval. This could become manifest during

Footnote 11 continued

empathizing? The scope of the impartial spectator in the ape story is determined by a situation that gives rise to mutual exchanges of point of view: a collective action problem in the wild.

12 On the general idea that organisms can trade various goods and services with each other: biological market theory, e.g. Noë et al. (1991, 2001). Specifically for chimpanzees, see De Waal (1997), Gomes and Boesch (2009).

13 Of course there is an interesting issue whether all this exchange and cooperation will be sufficiently stable. It goes beyond the scope of this paper to argue for this but, very briefly, there would be an important role not only for the on the spot corrections by the bystanders, but also for a measure of reputation effects and a primitive form of gossip (indirect reciprocity). See various contributions in Hammerstein (2003). 
encounters in which a dominant individual might get away with defection but makes no attempt. Primatologists characterize chimpanzee communities as "fission-fusion societies." Their communities are continuously dissolved in varying subgroups. These subgroups vary in spatial cohesion, in group size and in group composition. ${ }^{14}$ Chimpanzee communities are highly fluid in all three dimensions, which makes their social life cognitively quite demanding. Now as no chimp will be able to constantly monitor and keep track of the others' movements, actions, and transactions, there is ample room for free riding. Such circumstances, more specifically a sudden change in group composition, provide good empirical conditions for testing whether somebody else's cooperation makes up a reason as such, because this arguably makes the situation resemble a one shot game. Since a captor should share with whoever has participated in the hunt, whether the other party can be regarded as an incidental visitor or not, whether the captor is oneself on the brink of leaving for quite some time or not.

Thus our cooperative Taï chimpanzees share on the basis of cooperation, not social appraisal. Therefore, we continue, Alfa shares with Beta (and believes that he does so, we have already dealt with this) because Beta cooperated. Or can't we say this? Is this 'because' sound? Why not say that the two events are merely associated? There is some sharing done when there has been cooperation.

The question is how to get a 'because'-in the sense of an answer to a 'why?' question. First, let's assume that the causal sequence is straight, and that there are no spurious associations. The sharing should really relate to the fact of cooperation. Of course, Beta might have cooperated, but he is possibly also a cousin, a mate, or an ally. Now it should not be such extraneous information about Beta that really guides Alfa's choice. Assume that there is enough field data and that a multiple regression analysis which includes kinship, relationship quality, rank difference, sex combination, other services provided, and whether Bet has participated in the hunt, can rule out any spurious correlations.

We have supposed that the propositional attitude capacity is already in place. So not only do our chimps share, they also believe that this is what they should do. Now we, thanks to Christophe and Hedwige Boesch, know that cooperation causes the sharing, but of course that need not imply that the one who does the sharing believes this. Perhaps Alfa shares with Beta because Alfa likes Beta, which is subliminally caused by the cooperation event - comparable to falling in love with somebody for untellable pheromonic reasons. Would it be enough if we made the fact of cooperation a subject of belief? Then the case could still be this: Alfa believes that he shares with Beta, and Alfa believes that Beta has just cooperated, with these two beliefs interestingly co-varying, within Alfa's mind, but not for Alfa. In this situation it seems that Alfa doesn't know why he likes Beta. "I just do," would be his answer, if he could talk. To rule out such rash sympathy, suppose that Beta has participated in the hunt all right, and then goes to Alfa, and does something mildly hostile, like sticking out his tongue, and then holds out for a bite. Then, in our idealization, Alfa should still share with Beta. If this happens then, I presume, likeability wasn't Alfa's reason after all. And if one retorts that this is a special

14 E.g. see Aureli et al. (2008). 
likeability, which only projects onto cooperators, then, of course, everything is fine. With this outward behavior I suppose that the penny has dropped for Alfa. He rationally connects his beliefs about sharing and about Beta. Alfa shares with Beta because Beta has cooperated. ${ }^{15}$ We can say that thanks to this 'because', through this rational linkage between a belief about cooperation and a belief about appropriate sharing, our apes now have a sense of merit. For them, the issue of how to distribute depends on who took part in the cooperative venture.

We could go further still, bring in the Quinean thesis about radical interpretation, and suppose that Alfa sees matters under a different description. He doesn't think of a collective hunt, but sees some elaborate group dance around a screaming monkey that always ends with the same shrill tones. Suppose the mapping is one on one, that there is empirical equivalence across the board, and no conceivable test for our friend to distinguish a cooperative hunt from this special choreography. He would share with anybody who makes the right dancing moves in the dance, moves which precisely correspond with blocking and chasing moves as seen by his comrades. Does this constitute a problem for our purposes here? I don't think it does, because it is still the case that this dancing Alfa shares for a reason. He shares because others have performed their dance parts properly. More importantly, we have this problem too, if it is a problem. Perhaps somebody behaves morally to serve some secret deity, a deity who completely agrees with the prevailing system of morality. Such a person would behave exactly like a moral person, and, though perhaps not your friend, be just as trustworthy in matters of cooperation. Behavioral facts always underdetermine mental ascription.

Thus if the causality runs straight, and the chimp holds a belief that he should share with someone that is causally linked with a belief about that creature's cooperation, then conclude that this cooperation is the chimp's reason for sharing.

\section{Mutual beliefs}

Our apes share the loot with those who helped to produce it, those who cooperated. So it is largely the fact of cooperation that determines how distribution is settled. But isn't this still too simple? Consider this scenario.

Some members of the group have lost their appetite for meat due to some allergy. Eating meat makes them sick. However, they have not lost their interest in the hunt, their killer instinct (assume that the meat allergy and the killer instinct derive from distinct genetic locations). They are confused, these apes, but suppose that their work as blockers and chasers is impeccable. Now when these individuals have cooperated in the hunt they do not expect a share. Neither, it seems, should these vegetarians get a share of the loot. Would it be the right thing to do for a captor to catch them up, when they are already on their way to pick a coconut, bring them to standstill, and then-here, have this-distribute? That seems to be forced. Sharing no matter what with anybody who simply cooperated, i.e. without a concern for what the other party thinks about the issue, seems dogmatic, disconnected.

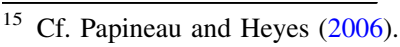


The attitude of the other party should count, too. The ape should be sensitive to the relevant beliefs of the receiver.

The expectations on the part of the receiver should play a role in the mind of the captor. Empirical support would be given by captors sharing with fellow hunters who hold out their hands, and by the same captors not sharing with fellow cooperators who have no such expectations, for example the vegetarians. ${ }^{16}$ If we see this, then we may conclude that the chimps share not only on the basis of cooperation but also attend to or be aware of the attitude of the potential receiver. ${ }^{17}$ This means that the captor believes that a fellow cooperator believes that he should get a share. Thus beliefs about another creature's beliefs have now entered our ape world. Yesterday Alfa, as captor, believed that Beta, as blocker, believed that Beta should get a share. Today Beta, now captor, believes that Alfa, now blocker, believes that Alfa should get a share. Their beliefs are now mutually referring.

Without mutual beliefs about what should be done the captors would look like disconnected myopic do-gooders, who share on the basis of cooperation but without further concern about what is on the mind of the receiving side. I am not saying that this cannot work. Everything could interlock just fine in such a society. But to count as a moral society, the interlocking or connection of the sharing and the receiving should not merely be the result of invisible hand dynamics. It should take place (or at least be reconstructable from) within the minds of the inhabitants of that society. This happens through mutual beliefs.

There is a difference between having a belief about another creature having a belief and having a belief merely on the basis of approval-disapproval triangulation, as in section "Belief". In the latter situation Alfa fine-tunes his conceptions about sharing after a hunt, through the signals that he receives from the others. For all he knows, those others may simply be airing their feelings. Ascribing a belief to them is going one step further. (It is a step we need for arriving at first person moral objectivity). However, distinguishing the two possibilities is empirically intricate. How can one tell whether an ape has changed the course of his conduct merely because of someone else's grunt or because of a certain mental state in that same individual? At this point in our investigation, it seems that connecting requirements and behavioral correlates has become especially troublesome. Again, behavioral facts underdetermine mental ascription, but with mutual beliefs, belief about beliefs, this problem multiplies. Indeed, it is exactly here that a frontier of current primate research can be found: on the possible range of primate theories of mind and the proper ways to investigate this, e.g. Tomasello et al. (2003), Call and Tomasello (2008). So let me just pause here and merely locate the problem.

Arguably there is a second route to mutual beliefs (again from the counteractingdisconnectedness argument). Let's return to the chimpanzees after a group hunt. We have mostly concentrated on the captors and their fellow cooperators. It is time to

\footnotetext{
16 Real chimps almost never share with conspecifics who do not beg.

17 It can be argued that the expectations of the receiver should also be part of the reason for sharing for a captor, but I take a more modest line here. The captor should at least be aware of the receiver's expectations. That suffices for my purposes.
} 
involve the bystanders again. At the end of section "Belief", it is asserted that bystanders manifestly disapprove of captors who do not share with blockers and chasers. Then, of course, we assume that the bystanders satisfy the same set of conditions as the captors: belief, reason, mutual beliefs. (But then how does triangulation work for them? Simply, by means of the other bystanders. And so on). Thus in the end we have:

- Captors believe [what captors should do]. ${ }^{18}$

- Fellow cooperators believe [what captors should do].

- Bystanders believe [what captors should do].

In short, in the end everybody believes [what captors should do]. Now all along we have also assumed, but not made explicit, that the captors, fellow cooperators, and bystanders are not fixed groups, made up of always the same individuals. Recall that Alfa could be a captor this time, and a blocker, or a bystander the next. Thus the chimps shift through these roles. This implies for them, it is easy to suppose, that everyone believes that everyone, whatever the role he happens to occupy, believes [what captors should do]. Hence, at this point the reason for acting in a moral way has become independent of role or standpoint, in everybody's mind. This means that this way of cooperative behavior has now become part of the ape's moral point of view.

\section{Conclusion}

We started from De Waal's observations of occasional chimpanzee altruism, and transferred that to a real life chimpanzee collective action problem, namely food sharing after a group hunt.

My aim was to specify a set of intermediate conditions between helpful chimp and moral man. The conditions for not only seeing the appropriate sharing but also ascribing a belief appeared to involve a set of possibly approving and disapproving bystanders. Having an objectified belief and performing the cooperative action in this type of collective action problem is not enough however, because it does not manifestly differ from acting for the wrong kind of reasons. Cooperation must be the real cause, not social appraisal. Furthermore, cooperation should not be just a cause, it should make up the reason. Finally, it is not just the fact of cooperation that should play a role, but also as it figures in the attitude of the other party, thereby yielding mutual beliefs:

The chimp shares food.

The chimp believes that he should share food.

The chimp believes that he should share food because the receiver has cooperated.

The chimp believes that everybody believes that he should share food because the receiver has cooperated.

$\overline{18}$ This stands for: [captors should share with fellow-cooperators]. 
Thus we have worked, via the chimps, towards objective morality as conceived from a first person point of view in terms of propositional attitudes and reasons. I have chosen this end point because, firstly, in a moral world it is not so that each individual simply believes what should be done, each on his own, with all merely converging on the moral truth. What should be done is a public fact in a moral society: everybody believes this about each other. This 'everyone believes that everyone, whatever the role he happens to occupy, believes what should be done' establishes a moral norm. From this norm things can be deduced, if one wants, e.g. that Kappa, as a fellow cooperator, now has reason to find that Zeta, as a captor, should share with him. My second reason is that one has to stop somewhere, and at this point I frankly see no good reason for not calling our apes moral creatures.

The Taï chimpanzee group hunt with the subsequent sharing behavior functioned as the starting point for our constructional tale. But of course somebody else's participation in a cooperative project is not the only legitimate reason to act morally. Morality is not confined to collective action contexts. Doing one's part in a cooperative project is a good reason for getting a share of the spoils; but so is the fact that the other is in need, has a wish, or is in pain. So let us be pluralistic and say that these reasons do not reduce to each other. I have chosen a collective action context, with the bystanders possibly disapproving and the chasers and blockers expecting something, because it quite easily helps to develop my case. So let us now generalize and return to one of De Waal's cases. Recall Jakie helping Krom with the tires. Why would Jakie do this, if we want to think of him as a moral creature? Suppose that the right reason for Jakie to help Krom is that Krom needs help. Then apply the same $\operatorname{logic}{ }^{19}$ :

Jakie helps Krom.

Jakie believes that he should help Krom.

Jakie believes that he should help Krom because Krom needs help.

Jakie believes that everybody believes that he should help Krom because Krom needs help.

Hence, I claim that with the right kind of reason in place the same requirements are appropriate, with corresponding behavioral correlates as far as that goes. A moral ape not only benefits or helps somebody, he also believes he does so, on the basis of the right kind of reason, and believes that everybody thinks that this is what should be done.

Open Access This article is distributed under the terms of the Creative Commons Attribution Noncommercial License which permits any noncommercial use, distribution, and reproduction in any medium, provided the original author(s) and source are credited.

\footnotetext{
19 The idea is that the requirements 'belief', 'right kind of reason' (matched with pluralism) 'mutual beliefs', and the global objective of 'first person objectivity' are sufficiently general to legitimate this.
} 


\section{References}

Aureli F, Schaffner C, Boesch C, Bearder S, Call J, Chapman C, Connor R, Fiore A, Dunbar R, Henzi S, Holekamp K, Kostjens A, Layton R, Lee P, Lehmann J, Manson J, Ramos-Fernandez G, Strier K, van Schaik C (2008) Fission-fusion dynamics. Curr Anthropol 49:627-654

Bennet J (1964) Rationality. An essay towards an analysis. Hackett, Indianopolis

Boesch C (1994) Cooperative hunting in wild chimpanzees. Animal Behav 48:653-667

Boesch C (2003) Complex cooperation among Taï chimpanzees. In: de Waal F, Tyack P (eds) Animal social complexity. Harvard University Press, Cambridge

Boesch C (2005) Joint cooperative hunting among wild chimpanzees: taking natural observations seriously. Behav Brain Sci 28:692-693

Boesch C, Boesch H (1989) Hunting behavior of wild chimpanzees in Taï national park. Am J Phys Anthropol 78:547-573

Call J, Tomasello M (2008) Does the chimpanzee have a theory of mind? 30 years later. Trends Cogn Sci 12:187-192

Davidson D (1982) Rational animals. Dialectica 36:317-327

de Waal F (1996) Good natured: the origins of right and wrong in humans and other animals. Harvard University Press, Cambridge

de Waal F (1997) The chimpanzee's service economy: food for grooming. Evol Hum Behav 18:375-386 de Waal F (2006) Primates and philosophers. How morality evolved. Princeton University Press, Princeton de Waal F (2007) With a little help from a friend. Plos Biol 5(7):1406-1408

Dennett D (1995) Darwin's dangerous idea. Evolution and meanings of life. Simon and Schuster, New York

Dretske D (2006) Minimal rationality. In: Hurley S, Nudds M (eds) Rational animals?. Oxford University Press, Oxford

Gomes C, Boesch C (2009) Wild chimpanzees exchange meat for sex on a long term basis. Plos Biol 4(4): $1-6$

Grice P (1975) Method in philosophical psychology (from the banal to the bizarre). In: Proceedings and adresses of the American Philosophical Association, pp 23-53

Hammerstein P (ed) (2003) Genetic and cultural evolution of cooperation. The MIT Press, Cambridge

Harnden-Warwick D (1997) Psychological realism, morality, and chimpanzees. Zygon 32:29-40

Kitcher P (1998) Psychological altruism, evolutionary origins, and moral rules. Philos Stud 89:283-316

Kitcher P (2006) Ethics and evolution. How to get here from there. In: de Waal F (ed) Primates and philosophers. How morality evolved. Princeton University Press, Princeton

Korsgaard C (2006) Morality and the distinctiveness of human action. In: de Waal F (ed) Primates and philosophers. How morality evolved. Princeton University Press, Princeton

Millikan R (2006) Styles of rationality. In: Hurley S, Nudds M (eds) Rational animals?. Oxford University Press, Oxford

Noë R, van Schaik C, van Hooff J (1991) The market effect: an explanation for pay-off asymmetries among collaborating animals. Ethology 87:97-118

Noë R, van Hooff J, Hammerstein P (2001) Economics in nature: social dilemmas mate choice and biological markets. Cambridge University Press, Cambridge

Papineau D, Heyes C (2006) Rational or associative? Imitation in Japanese quail. In: Hurley S, Nudds M (eds) Rational animals?. Oxford University Press, Oxford

Searle J (1994) Animal minds. Midwest studies in philosophy 19:206-219

Singer P (2006) Morality, reason, and the rights of animals. In: De Waal F (ed) Primates and philosophers. How morality evolved. Princeton University Press, Princeton

Skyrms B (1996) Evolution of the social contract. Cambridge University Press, Cambridge

Smith A (1759) The theory of moral sentiments. Oxford University Press, Oxford

Tomasello M, Call J (1997) Primate cognition. Oxford University Press, New York

Tomasello M, Call J, Hare B (2003) Chimpanzees understand psychological states-the question is which ones and to what extent. Trends Cogn Sci 7:153-156

Tomasello M, Carpenter M, Call J, Behne T, Moll H (2005) Understanding and sharing of intentions: the origins of cultural cognition. Behav Brain Sci 28:675-735

van Hooff J (1972) A comparative approach to the phylogeny of laughter and smiling. In: Hinde R (ed) Non-verbal communication. Cambridge, Cambridge University Press

van Hooff J, Preuschoft S (2003) Laughter and smiling: the intertwining of nature and culture. In: de Waal F, Tyack P (eds) Animal social complexity. Harvard University Press, Cambridge 